\title{
The Impact of River Contractions on the Bed Morphology under Unsteady Flows
}

\author{
Giuseppe Oliveto \\ School of Engineering, University of Basilicata, Viale dell'Ateneo Lucano 10, Potenza I-85100, Italy
}

Corresponding Author Email: giuseppe.oliveto@unibas.it

https://doi.org/10.18280/ijsdp.150208

Received: 16 August 2019

Accepted: 10 February 2020

\section{Keywords:}

bed load, channel contraction, erosion, unsteady flow

\begin{abstract}
Flow constrictions occur when canals or rivers are subjected to a reduction in width because of natural constraints (e.g. debris accumulations, longitudinal bars, confluences) or hydraulic works (e.g. bridge embankments, guide banks, spur dikes). This paper aims to provide new insights on the temporal evolution of the bed profiles at and downstream of river contractions based on special experiments at laboratory scale. In a previous experimental campaign at University of Basilicata, Italy, several runs were performed under steady flow and clear-water scour conditions. In this study new experiments are presented under unsteady flow conditions. Six experiments were carried out considering stepped hydrographs of different shapes. Laboratory tests were performed in a $20 \mathrm{~m}$ long straight channel having a rectangular cross section $1.0 \mathrm{~m}$ wide and $1.0 \mathrm{~m}$ deep. The working section was made by almost uniform coarse sand. The contraction model was $1.0 \mathrm{~m}$ long and the contraction ratio (i.e. the ratio of the width of the uniformly contracted area to the width of the undisturbed channel) equal to 0.80 . The experiments were performed under clear-water scour regime also for the peak discharges. Starting from novel empirical formulas related to steady flow conditions, an approach is proposed for the prediction over time and along the channel centreline of the maximum (contraction) scour depth, the scour hole length, and the bed profile. Comparison between observed data and predicted values reveals a satisfactory agreement. The relationships here introduced appear to be suitable for practical purposes.
\end{abstract}

\section{INTRODUCTION}

Flow constrictions take place when canals or rivers are constrained by significant reduction in width. In case of subcritical approach flows, the flow concentration and the increase of flow velocity in the contracted area might determine local and general scour processes at and around the watercourse constriction.

In a very early paper, Straub [1] highlights how river contractions frequently occur when structures are built in restricting the river to achieve greater navigable flow depths. Lim [2] emphasizes how examples of river contractions are the gradual closing of a river prior to the construction of a dam or the partial constriction of a river either to build a spur dike into the flowing water or a cofferdam to enclose the work area for a structure from one side of the riverbank. Gill [3] shows how the river channel within the parallel guide banks, built on diversion works such as weirs and barrages, is a practical example of rectangular long contraction. As a real case, Gill [3] illustrates the significant reduction in width of the Sutlej River (at Mailsi Siphon), Pakistan, from $12 \mathrm{~km}$ to $432 \mathrm{~m}$. Last but not least, the constriction of a watercourse is a common condition at many bridge sites.

There are several papers in the literature dealing with experimental works at laboratory scale on contraction scour. Among them are the studies by Laursen, Komura, Webby, Gill, Lim, Lim and Cheng, and Dey and Raikar [2-8]. In particular, Webby [6] used a somewhat large channel with upstream and contracted widths equal to $1.586 \mathrm{~m}$ and 0.524 $\mathrm{m}$, respectively, and therefore he analysed experimental conditions with significant contraction ratio. The contraction length was equal to $4.375 \mathrm{~m}$. Webby [6] carried out 12 experiments and for the experiments I and II he provides detailed information on the temporal development of the water surface and bed profiles along the channel centreline. Dey and Raikar [8] provide detailed information on 131 scouring experiments considering long contractions (i.e. the ratio of the length of the uniform contracted reach to the width of the uncontracted channel is greater than 1-2). 99 experiments involved nearly uniform sediments and the remaining 32 non-uniform sediments. Tests were carried out in a $12 \mathrm{~m}$ long, $0.6 \mathrm{~m}$ wide, and $0.7 \mathrm{~m}$ deep flume. The uniform contraction zone was $1 \mathrm{~m}$ long.

Some studies focus on particular, but important, conditions at river contractions. Dey and Raikar [9] suggested an approach based on the energy and continuity equations to estimate the equilibrium scour depth under approach live-bed conditions. They used 31 experiments from literature (i.e. 4 experiments from Komura [5], 20 from Gill [3], and 7 from Lim [2]) to validate their approach. The range of variation of the flow intensity (i.e. the ratio of the approach flow velocity to the critical flow velocity at the bed sediment inception) was from 1.01 up to 1.52. The Authors also emphasize how, among the predictive models available in the literature, the equation recommended by Lim [2] would provide the more reasonable estimation of the scour depth. Brandimarte et al. [10] proposed a mathematical model to estimate the contraction scour depth over the life of a bridge under clear- 
water conditions and unsteady flows. The model is based on the energy and continuity equations and an empirical expression for the scour rate in cohesive soils.

Experimental data on contraction scour at field scale are very few. Benedict [11] provides a total of 76 observations of clear-water contraction scour at 53 bridge sites in the South Carolina Piedmont. Scour depths ranged from 0 to $4.5 \mathrm{ft}$. The dense vegetation and low velocities at the investigated sites typically determined clear-water scour conditions at the bridge overbanks. Mueller and Wagner [12] presented realtime contraction scour measurements at contracted bridge openings spanning the Pomme de Terre River, in the Minnesota River basin. Measurements were collected during the flooding in April 1997. They found that the current methodologies for computing contraction (and local) scour did not compare well with the observed data. The accuracy of the contraction (and abutment) scour equations may depend on the degree of the contraction and the flow distribution. Hayden and Puleo [13] present the results of a new scour monitoring system using three-dimensional profiling sonars installed on the Indian River Inlet bridge, Delaware, to observe more than $19,000 \mathrm{~m}^{2}$ of bathymetry daily. Interestingly, the monitored area shows morphological bed patterns that look similar to those observed at the contraction physical models generally used in the laboratory.

Despite the large number of literature studies, the knowledge on bed morphological changes at and around river contractions is still lacking. The analysis of the experimental data is mainly focused on the maximum scour depth, leading aside many other features of the bed morphology also downstream of the contracted area. Moreover, existing predictive models consider dynamic equilibrium conditions, missing the effect of time. This paper aims to provide some advances in this context. New special laboratory experiments are presented. They, along with previous ones carried out at University of Basilicata, Italy, Oliveto and Marino, and Oliveto [14-17] have allowed to develop predictive models on the temporal evolution of the bed profile, at and downstream of the contracted area, under both steady and unsteady flows.

\section{LABORATORY EXPERIMENTS}

In recent years several experiments have been carried out at the Hydraulic Engineering Laboratory, University of Basilicata, on the morphological bed processes at river contractions under steady flows and clear-water scour conditions. To this end, a straight rectangular channel has been used $20 \mathrm{~m}$ long, $1 \mathrm{~m}$ wide and $1 \mathrm{~m}$ deep. Most of the runs have been performed by using an almost uniform coarse sand for the mobile bed with median grain size $d_{50}=1.7 \mathrm{~mm}$, sediment gradation $\sigma=\left(d_{84} / d_{16}\right)=1.5$, and dimensionless grain size $D^{*}=\left(g^{\prime} / v^{2}\right)^{1 / 3} d_{50}=39.4 . v$ is the kinematic viscosity of water and $g^{\prime}$ is the modified gravitational acceleration equal to $g\left(\rho_{s}-\rho\right) / \rho$, with $\rho$ mass density of water, $\rho_{s}$ mass density of sediment, and $g$ gravitational acceleration. Selected few runs have been conducted by using gravel with $d_{50}=9.0 \mathrm{~mm}$, $\sigma=1.5$, and $D^{*}=228$ to assess the effects of the sediment grain size. In both cases, viscosity effects at the interface flow-sediment could be considered negligible because $D^{*}>10-20$ [18]. Three ratios $\beta=b / B$ for the constriction have been used with $b$ the width of the uniformly contracted area and $B$ the width of the undisturbed channel. Namely, $\beta$ was either 0.90 or 0.80 , or 0.70 . The ratio of $b$ to the approach flow depth was always greater than (or close to) 5 to minimize sidewall effects [19]. The length $l$ of the uniformly contracted reach was either 0.5 or 1.0 or 2.0 , or $3.0 \mathrm{~m}$ including in this way both short (i.e. $l / B \leq 1$ according to [5]) and long contractions. More details on the experiments and main test conditions and observations are given [14-17].

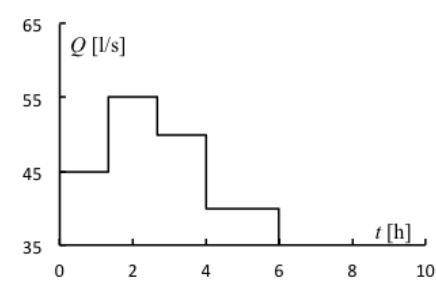

(a)

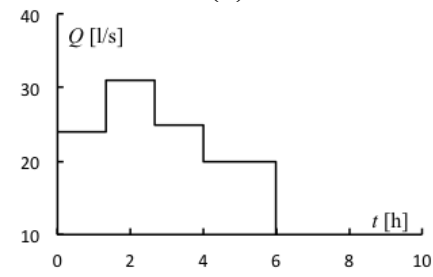

(b)

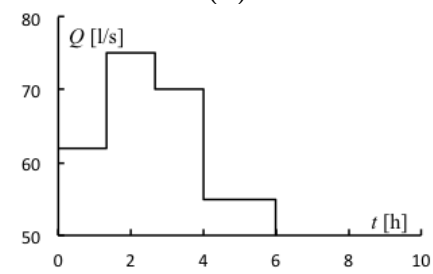

(c)

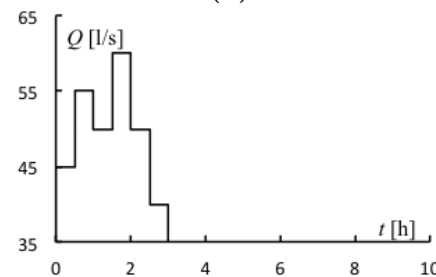

(d)

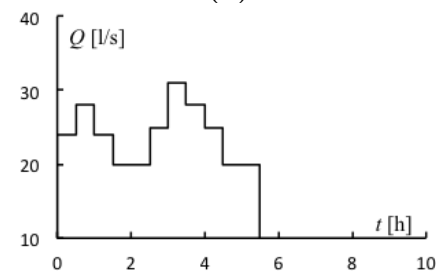

(e)

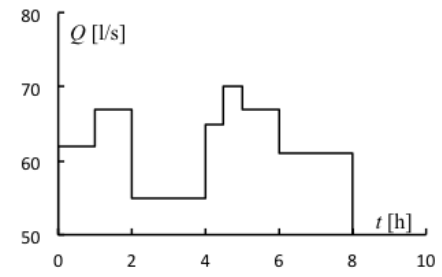

(f)

Figure 1. Stepped hydrographs considered in the present study. (a) Experiment UF\#1 with $Q_{\max }=55.0 \mathrm{l} / \mathrm{s}$ and $h_{o, \max }=0.126 \mathrm{~m}$; (b) UF\#2 with $Q_{\max }=31.0 \mathrm{l} / \mathrm{s}$ and $h_{o, \max }=0.070 \mathrm{~m}$; (c) UF\#3 with $Q_{\max }=75.0 \mathrm{l} / \mathrm{s}$ and $h_{o, \max }=0.165 \mathrm{~m}$; (d) UF\#4 with $Q_{\max }=60.0 \mathrm{l} / \mathrm{s}$ and $h_{o, \max }=0.116 \mathrm{~m}$; (e) UF\#5 with $Q_{\max }=31.0 \mathrm{l} / \mathrm{s}$ and $h_{o, \max }=0.066 \mathrm{~m}$; and (f) UF\#6 with $Q_{\max }=70.01 / \mathrm{s}$ and $h_{o, \max }=0.164 \mathrm{~m}$ 
In this study six new experiments were carried out under unsteady flow. To the Author's knowledge, at present there aren't experiments of this kind available in the literature. The mobile bed was $16 \mathrm{~m}$ long and made by the almost uniform sand, with $D^{*}=39.4$, previously described. The contraction model caused a contraction ratio $\beta=0.80$ and was $1.0 \mathrm{~m}$ long along the uniformly contracted area. The contraction inlet and outlet were identical in size (with a length of $0.25 \mathrm{~m}$ ) and shape (triangular shape). The upstream end of the contraction inlet was located $6.0 \mathrm{~m}$ from the beginning of the mobile bed, thus allowing fully turbulent approach flows. The mobile bed from the downstream end of the contraction outlet to its downstream end was $6.0 \mathrm{~m}$ long, thus allowing an almost complete development of bed aggradation and degradation processes. Stepped hydrographs were used, since real-shaped hydrographs were difficult to get. Single and double peaks hydrographs were considered with time step $\Delta t$ ranging from 0.5 to 2 hours. Figure 1 shows the shape and the discharge values over the time for each of the six hydrographs considered in this study. Overall, the time steps for the rising limb were smaller than those for the recessing limb, as usually happens in the reality. The change of discharge from one step to the next one was performed gradually to minimize flow acceleration or deceleration. The flow discharge was set adjusting the inlet valve installed in the feeding pipe. The flow depth in the channel was controlled with a rectangular sharp crested weir located at the downstream channel end. After carefully flattening the mobile bed, the channel was gradually filled without any sediment movement under submerged flow. Subsequently, the discharge was increased up to the desired value; then the flow depth was reduced to its established value by lowering the weir. Then, the experiment started under the first hydrograph step. For the remaining steps the discharge varied while the height of the sharp-crested weir remained unchanged. All the experiments were designed to guarantee clear-water scour conditions also for the peak discharges. During each experiment from two to three surveys were carried out with special attention to the longitudinal bed profile around the channel centreline. The flow discharge was measured, with an accuracy of $\pm 3 \%$, by an orifice plate installed into the circuit pipeline; flow depths were measured by a point gage with an accuracy of $\pm 0.1 \mathrm{~mm}$, and bed levels were measured with a shoe-gage, of the type described by Oliveto et al. [14], Oliveto and Marino [15, 16], with an accuracy of the order of the grain size.

For each experiment Table 1 provides the main test conditions in terms of discharge $Q$, approach flow depth $h_{o}$, Reynolds number $R e$, Froude number $F$, densimetric Froude number $F_{d}$, and densimetric Froude number $F_{d i}$ for incipient movement of the bed sediment grains $\left(F_{d} \leq F_{d i}\right.$ implies clear- water scour conditions while $F_{d}>F_{d i}$ live-bed conditions). All the above parameters relate to the approach flow and to a specific time-step $\Delta t$. Moreover, the reader is referred to the previous papers [14-17] for the definition of $F_{d}$ and $F_{d i}$. It can be noted that $R e$ was always greater than (or close) to $10^{5}$ (i.e. rough turbulent flows) and $F_{d}$ always lower than $F_{d i}$ (i.e. clear-water scour).

Figure 2(a) shows the water surface at the contraction area and downstream during the experiment UF\#1. In general, there was a small increase in the flow depth upstream of the contraction model above the flow depth in absence of the contraction (referred to as approach flow depth in this study), as expected for subcritical approach flows. Approach flow streamlines are forced to converge at the channel centreline in a zone located more than half of the uniformly contracted reach length and a little upstream of the contraction outlet. Then the flow streamlines tend to diverge, thereby causing the development of small waves that propagate downstream. Figure 2(b) shows the bed morphology at the end of the experiment UF\#1 after the channel was drained. Local scour holes (of the type abutment scour) at the contraction inlet can be clearly identified. It is interesting to observe as these scour holes extend along the sidewalls in the contracted area and even downstream. An aggradation area was evident just downstream of the contraction outlet close to the walls of the undisturbed channel. It is also guessed from Figure 2(b) that a bed degradation occurred along the channel centreline at the contracted area and also downstream.

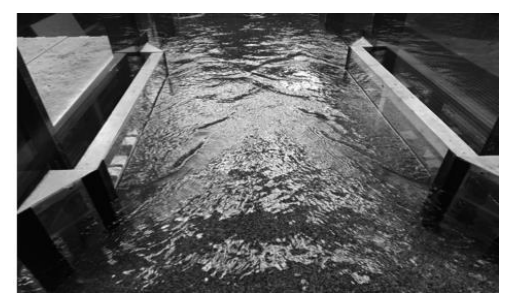

(a)

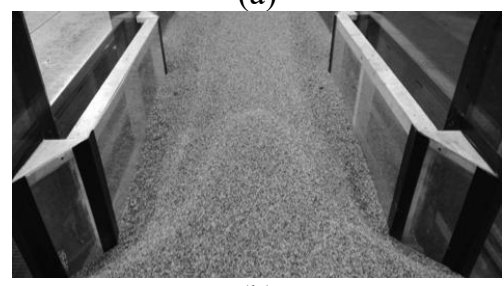

(b)

Figure 2. Experiment UF\#1 with maximum discharge $Q=0.055 \mathrm{~m}^{3} / \mathrm{s}$, and maximum approach flow depth $h_{o}=0.126$ $\mathrm{m}$. Views from upstream to downstream. (a) Water surface during the experiment and (b) Bed morphology at the end of the experiment after the channel was drained

Table 1. Main test conditions for each experiment (UF\#) in terms of: time step $\Delta t$ (in hours), flow discharge $Q$ (in L/s), approach flow depth $h_{o}$ (in cm), Reynolds number $R e$ (multiplied by $10^{-5}$ ), Froude number $F$, densimetric Froude number $F_{d}$, and inception densimetric Froude number $F_{d i}$

\begin{tabular}{cccccccccc}
\hline \multicolumn{10}{c}{ UF\#1 Hydrograph time-step } \\
\hline & 1 & 2 & 3 & 4 & 5 & 6 & 7 & 8 & 9 \\
\hline$t$ & 1.33 & 1.33 & 1.33 & 2.00 & - & - & - & - & - \\
$Q$ & 45.0 & 55.0 & 50.0 & 40.0 & - & - & - & - & - \\
$h_{o}$ & 10.8 & 12.6 & 11.8 & 10.7 & - & - & - & - & - \\
$R e$ & 1.30 & 1.50 & 1.40 & 1.20 & - & - & - & - & - \\
$F$ & 0.40 & 0.39 & 0.39 & 0.36 & - & - & - & - & - \\
$F_{d}$ & 2.51 & 2.63 & 2.55 & 2.25 & - & - & - & - & - \\
$F_{d i}$ & 3.25 & 3.31 & 3.29 & 3.24 & - & - & - & - & - \\
\hline
\end{tabular}




\begin{tabular}{|c|c|c|c|c|c|c|c|c|c|}
\hline \multicolumn{10}{|c|}{ UF\#2 Hydrograph time-step } \\
\hline$t$ & 1.33 & 1.33 & 1.33 & 2.00 & - & - & - & - & - \\
\hline$Q$ & 24.0 & 31.0 & 25.0 & 20.0 & - & - & - & - & - \\
\hline$h_{o}$ & 6.0 & 7.0 & 6.2 & 5.5 & - & - & - & - & - \\
\hline $\operatorname{Re}$ & 0.75 & 0.95 & 0.78 & 0.63 & - & - & - & - & - \\
\hline$F$ & 0.52 & 0.53 & 0.52 & 0.50 & - & - & - & - & - \\
\hline$F_{d}$ & 2.41 & 2.67 & 2.43 & 2.19 & - & - & - & - & - \\
\hline$F_{d i}$ & 2.98 & 3.05 & 3.00 & 2.95 & - & - & - & - & - \\
\hline \multicolumn{10}{|c|}{ UF\#3 Hydrograph time-step } \\
\hline$t$ & 1.33 & 1.33 & 1.33 & 2.00 & - & - & - & - & - \\
\hline$Q$ & 62.0 & 75.0 & 70.0 & 55.0 & - & - & - & - & - \\
\hline$h_{o}$ & 15.0 & 16.5 & 15.4 & 14.4 & - & - & - & - & - \\
\hline $\operatorname{Re}$ & 1.70 & 2.00 & 1.90 & 1.50 & - & - & - & - & - \\
\hline$F$ & 0.34 & 0.36 & 0.37 & 0.32 & - & - & - & - & - \\
\hline$F_{d}$ & 2.49 & 2.74 & 2.74 & 2.30 & - & - & - & - & - \\
\hline$F_{d i}$ & 3.39 & 3.43 & 3.40 & 3.37 & - & - & - & - & - \\
\hline \multicolumn{10}{|c|}{ UF\#4 Hydrograph time-step } \\
\hline$t$ & 0.50 & 0.50 & 0.50 & 0.50 & 0.50 & 0.50 & - & - & - \\
\hline$Q$ & 45.0 & 55.0 & 50.0 & 60.0 & 50.0 & 40.0 & - & - & - \\
\hline$\hat{h}_{o}$ & 9.5 & 10.9 & 10.5 & 11.6 & 10.5 & 9.0 & - & - & - \\
\hline $\operatorname{Re}$ & 1.30 & 1.60 & 1.50 & 1.70 & 1.50 & 1.20 & - & - & - \\
\hline$F$ & 0.49 & 0.49 & 0.47 & 0.48 & 0.47 & 0.47 & - & - & - \\
\hline$F_{d}$ & 2.86 & 3.04 & 2.87 & 3.12 & 2.87 & 2.68 & - & - & - \\
\hline$F_{d i}$ & 3.19 & 3.25 & 3.23 & 3.28 & 3.23 & 3.17 & - & - & - \\
\hline \multicolumn{10}{|c|}{ UF\#5 Hydrograph time-step } \\
\hline$t$ & 0.50 & 0.50 & 0.50 & 1.00 & 0.50 & 0.50 & 0.50 & 0.50 & 1.00 \\
\hline$Q$ & 24.0 & 28.0 & 24.0 & 20.0 & 25.0 & 31.0 & 28.0 & 25.0 & 20.0 \\
\hline$h_{o}$ & 6.3 & 6.5 & 5.8 & 5.5 & 5.9 & 6.6 & 6.4 & 6.2 & 5.6 \\
\hline$R e$ & 0.75 & 0.87 & 0.76 & 0.63 & 0.79 & 0.96 & 0.87 & 0.78 & 0.63 \\
\hline$F$ & 0.48 & 0.54 & 0.55 & 0.50 & 0.56 & 0.58 & 0.55 & 0.52 & 0.48 \\
\hline$F_{d}$ & 2.30 & 2.60 & 2.49 & 2.19 & 2.55 & 2.83 & 2.64 & 2.43 & 2.15 \\
\hline$F_{d i}$ & 3.01 & 3.02 & 2.97 & 2.95 & 2.98 & 3.03 & 3.01 & 3.00 & 2.95 \\
\hline \multicolumn{10}{|c|}{ UF\#6 Hydrograph time-step } \\
\hline & 1 & 2 & 3 & 4 & 5 & 6 & 7 & 8 & 9 \\
\hline$t$ & 1.00 & 1.00 & 2.00 & 0.50 & 0.50 & 1.00 & 2.00 & - & - \\
\hline$Q$ & 62.0 & 67.0 & 55.0 & 65.0 & 70.0 & 67.0 & 61.0 & - & - \\
\hline$h_{o}$ & 15.8 & 16.2 & 15.2 & 16.1 & 16.4 & 16.2 & 15.8 & - & - \\
\hline$R e$ & 1.70 & 1.80 & 1.50 & 1.70 & 1.90 & 1.80 & 1.60 & - & - \\
\hline$F$ & 0.32 & 0.33 & 0.30 & 0.32 & 0.34 & 0.33 & 0.31 & - & - \\
\hline$F_{d}$ & 2.37 & 2.49 & 2.18 & 2.43 & 2.57 & 2.49 & 2.33 & - & - \\
\hline$F_{d i}$ & 3.41 & 3.42 & 3.40 & 3.42 & 3.43 & 3.42 & 3.41 & - & - \\
\hline
\end{tabular}

\section{ANALYSIS OF DATA AND RESULTS}

In recent papers, Oliveto [17] and Oliveto and Marino [20] have suggested straightforward relationships for the temporal progress of the maximum scour depth $z^{*}$, the scour hole length $l^{*}$, and the bed profile along the channel centreline. In particular, Oliveto and Marino [20] have achieved the following predictive models also on the basis of literature data from Gill [3], Webby [6], and Dey and Raikar [8]:

$$
\begin{aligned}
& Z^{*}=0.1\left(\frac{h_{o}}{d_{50}}\right)^{-0.27}\left(1+\frac{l}{B}\right)^{0.60} \beta^{\prime 0.81} F_{d}{ }^{1.81} T^{0.10} \\
& L^{*}=8.9\left(\frac{h_{o}}{d_{50}}\right)^{-0.29}\left(1+\frac{l}{B}\right)^{0.64} \beta^{\prime-0.32} F_{d}{ }^{0.91} T^{0.04} \\
& Z=0.25 X^{4}-4.35 X^{3}+9.61 X^{2}-5.41 X-0.10
\end{aligned}
$$

with $\beta^{\prime}=(1-\beta) / \beta, Z^{*}=z^{*} / h_{o}, L^{*}=l^{*} / h_{o}$, and $T$ dimensionless time defined as $\left(g^{\prime} d_{50}\right)^{1 / 2} t / h_{o}$ where $t$ is the time, and $g^{\prime}$ the modified gravitational acceleration previously defined. With reference to Eq. (3), $Z$ is the ratio of the bed depth to the maximum scour depth $z^{*}$ and $X$ is the ratio of the distance of $z$ along the channel centreline and from the upstream end of the contraction inlet to the scour hole length $l^{*}$. From Eq. (1) it can be noticed that $Z^{*}$ is equal to zero when $\beta$ is equal to 1 (i.e. absence of contraction and clear-water scour regime) while $Z^{*}$ goes to infinity when $\beta$ goes to zero, as expected. Moreover, Eq. (3) is physically consistent with the condition that $Z=0$ for $X=1$. The above equations apply to steady flow conditions and their ranges of validity are: $18.81 \leq h_{o} / d_{50} \leq 117.65,0.50 \leq l / B \leq 3.00,0.70 \leq \beta \leq 0.90,1.08 \leq F_{d}$ $\leq 4.02$, and $1.0 \cdot 10^{3} \leq T \leq 2.1 \cdot 10^{6}$.

What fresh analysis of data supporting the above equations, Figure 3 shows the comparison between Eqns. (1) to (3) and two experiments from Webby [6] and one experiment from Lai and Greimann [21].

In both cases the experimental channels are rather large in size. The experimental stand used by Webby [6] has been described previously. Lai and Greimann [21] used a rectangular channel $16.5 \mathrm{~m}$ long and $1.0 \mathrm{~m}$ and $0.5 \mathrm{~m}$ wide for the undisturbed and contracted cross-sections, respectively. The centreline of the contraction model corresponds with the channel sidewall, therefore it's like the Authors have considered a channel $2.0 \mathrm{~m}$ wide with a uniformly contracted area $1.0 \mathrm{~m}$ wide. Overall, the agreement between the observed data and predicted values can be considered satisfactory, if the significant dimensions of the experimental stands are taken into account. In case of the experiments by Webby [6] several observed profiles appear 
to be affected by general erosion downstream of the contraction area and their understanding is somewhat difficult. Therefore, only two observed profiles have been considered here because also characterized by an aggradation zone. In case of the experiment by Lai and Greimann [21] the bed profile shape can be affected by the fact that it developed along the channel sidewall.

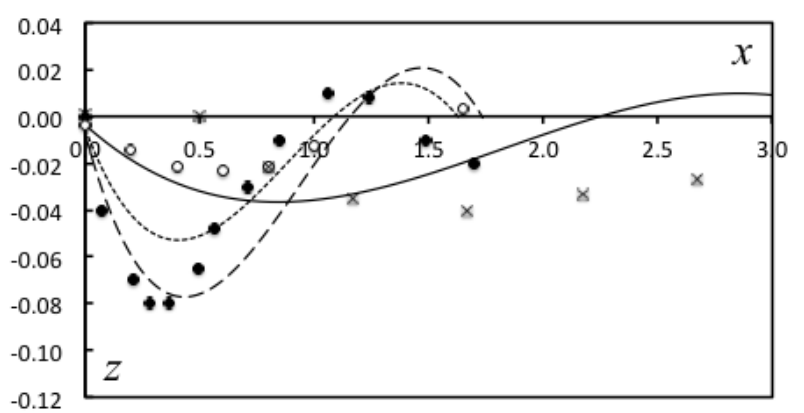

Figure 3. Comparison between observed and calculated values of $z$ (in meters) along the channel centreline. $x$ (in meters) is the distance of the point where $z$ occurs from the upstream end $(x=0)$ of the contraction model. The white circle and the dotted curve refer to the experiment I by Webby [6] at the time $t=12.5$ minutes, black symbols and dashed curve to the run II by Webby [6] at the time $t=4$ minutes, and cross symbols and full curve to the run 2 by Lai and Greimann [21] at the time $t=125$ minutes

In case of unsteady flows an approach similar to that used by Oliveto and Hager [22] for scour at bridge piers can be adopted. The prediction of the bed profile at a given time $t$ can be organized in the following steps:

- At the time $t=0$, the maximum scour depth $z^{*}$ is $=0$, and so too $l^{*}=0$;

- At the time $t_{1}=(\Delta t)_{1}$, with $(\Delta t)_{1}$ the first time-step of the hydrograph, one has $T_{1}=\left(g^{\prime} d_{50}\right)^{1 / 2} t_{1} / h_{o, 1}$ with $h_{o, 1}$ the approach flow depth at $(\Delta t)_{1}$. From Eqns. (1) and (2) the maximum scour depth $z_{1}{ }^{*}$ and scour length $l_{1}{ }^{*}$ can be calculated, respectively, and then the bed profile can be inferred from Eq. (3);

- In the time interval $\left(t_{1}, t_{2}\right)$, with $t_{2}=t_{1}+(\Delta t)_{2}$ and $(\Delta t)_{2}$ the second time-step of the hydrograph, the new approach flow depth is $h_{o, 2}$ and also the discharge has changed compared to the first step. This implies that also the densimetric Froude number, $F_{d, 2}$, is different from that, $F_{d, 1}$, of the first step. Therefore, at the time $t_{1}$ the dimensionless maximum scour depth $Z_{1}{ }^{*}$ is $z_{1}{ }^{*} / h_{o, 2}$ and the dimensionless scour hole length $L_{1}{ }^{*}$ is $l_{1}{ }^{*} / h_{o, 2}$. Hence, from Eqns. (1) and (2), in which $h_{o}=h_{o, 2}$ and $F_{d}=F_{d, 2}$, one can derive the dimensionless times $T_{1}$ and then the (fictitious) times $t^{\prime}{ }_{1}=T_{1} \cdot h_{o, 2} /\left(g^{\prime} d_{50}\right)^{1 / 2}$. Finally, one can compute the values of $z_{2}{ }^{*}$ and $l_{2}{ }^{*}$ from Eqns. (1) and (2) by considering the dimensionless time $T_{2}=\left(g^{\prime} d_{50}\right)^{1 / 2} t^{\prime} / h_{o, 2}$, with $t_{2}^{\prime}=t^{\prime}{ }_{1}+(\Delta t)_{2}$. The bed profile can, therefore, be inferred from Eq. (3);

- The same procedure as described above can be repeated until the last time-step of the hydrograph.

Figure 4 shows the comparison between the observed longitudinal bed profile at the end of each experiment performed in this study and the computed one by through the above approach. Similar results were found at the intermediate temporal steps. Results can be considered satisfactory taking into account the complexity of the problem and that the proposed approach implies three estimations; namely, the maximum scour depth by Eq. (1), the maximum scour hole length by Eq. (2), and the bed profile shape by Eq. (3). The greatest discrepancies would appear for the lowest values of the relative submergence ratio $h_{o} / d_{50}$ (see Figures 4(b) and (e)) when general erosion extends significantly downstream of the contraction area and the estimation of $l^{*}$ is not easy. It is also interesting to observe how the proposed approach tends to predict in an acceptable way the aggradation zone. Finally, for all the tests it is evident that the bed erosion extends downstream of the contraction area (the length of which is $1.5 \mathrm{~m}$ ), and therefore the knowledge about the maximum scour depth only is clearly a limited result.

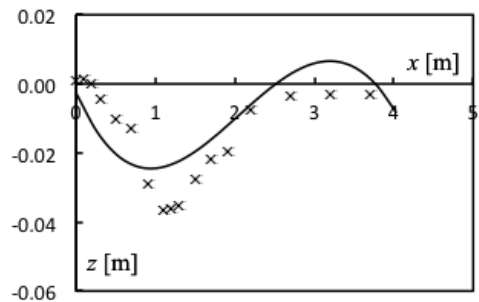

(a)

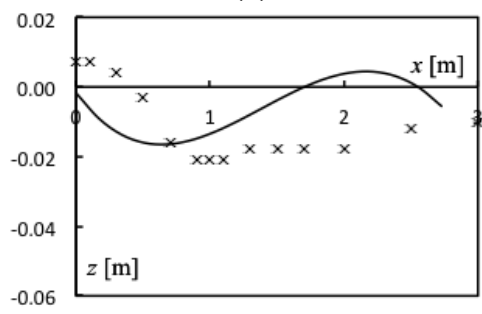

(b)

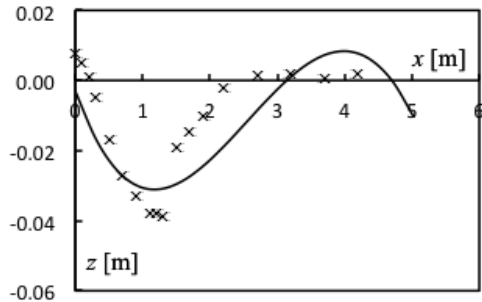

(c)

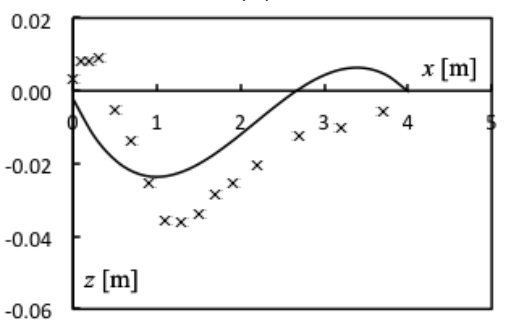

(d)

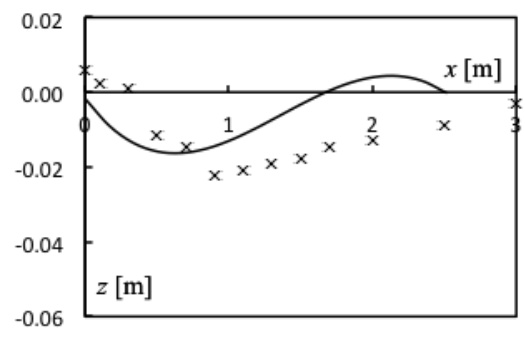

(e) 


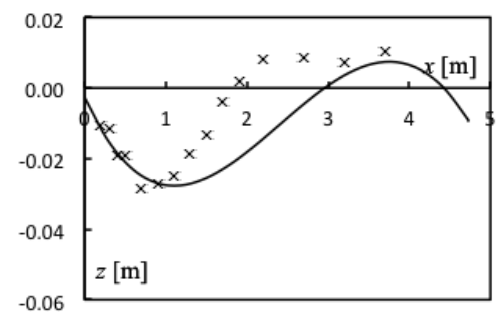

(f)

Figure 4. Comparison between the observed bed profile $(\times)$ at the end of each experiment and the computed one (full curve). (a) Experiment UF\#1; (b) UF\#2; (c) UF\#3; (d) UF\#4; (e) UF\#5; and (f) UF\#6. The $x$-axis corresponds to the undisturbed bed level and its origin coincides with the upstream end of the contraction inlet

\section{CONCLUSIONS}

New experiments at laboratory scale were performed in this study by simulating bed morphological processes at river contractions under unsteady flows and clear-water scour conditions. Six stepped hydrographs with one or two peaks were generated. Experimental conditions were designed to avoid/minimize scale effects. Fully developed turbulent flows were ensured by the suitable length (around $6 \mathrm{~m}$ ) of the approach mobile bed, approach flow Reynolds numbers were greater than (or at the most close to) $10^{5}$, viscosity effects at the interface fluid-sediment were minimized by using coarse sand with dimensionless grain size equal to 39.4 , and sidewall effects could be neglected because the ratio of the channel width to the flow depth was always greater than 5 also at the contracted zone.

Firstly, predictive models on the temporal progress of the maximum scour depth, the contraction scour hole length, and the dimensionless longitudinal bed profile around the channel centreline under steady flow and clear-water scour are presented and discussed. Some experiments available in scientific literature are considered to validate the predictive model on the longitudinal bed profile. Denoting with $Z$ the ratio of the bed level $(z)$ to the maximum scour depth $\left(z^{*}\right)$ and $X$ the ratio of the distance of $z$ from the upstream end contraction inlet to the contraction scour hole length $\left(l^{*}\right)$, the following experimental evidences were found (with some deviations) according to Eq. (3): (i) bed lowering of $Z=-0.10$ occurs at $X=0$ (i.e. upstream end of the contraction inlet); (ii) the maximum scour depth locates at $X=0.35$; (iii) the maximum aggradation depth is $Z=0.3$; and (iv) it locates at $X=1.30$

Starting from the proposed predictive models for steady flows (i.e. Eqns. from (1) to (3)), a computational procedure was developed to estimate the temporal evolution of the longitudinal bed profile at river contractions under unsteady flows. Experimental data are satisfactorily predicted with deviations generally acceptable. The highest discrepancies were found for the lowest values of the relative submergence ratio $h_{0} / d_{50}$ when general erosion extends significantly downstream of the contraction area and the estimation of $l^{*}$ is not easy. Anyway, there could be effects due to the flow acceleration or deceleration when moving through the hydrograph steps. And these effects are not accounted for by the computational procedure here proposed.

Further research projects might relate to the effects of the bed sediment non-uniformity, and the effects of live-bed approach flow conditions. From a research point of view the analysis of artificial materials with a density different from that of natural bed sediments would be of interest to deeply explore the effect of the densimetric Froude number.

\section{REFERENCES}

[1] Straub, L.G. (1934). Effect of channel-contraction works upon regime of movable bed-streams. Eos, Transactions, American Geophysical Union, 15(2): 454463. https://doi.org/10.1029/TR015i002p00454

[2] Lim, S.Y. (1993). Clear water scour in long contractions Proceedings of the Institution of Civil Engineers Water, Maritime and Energy, 101(2): 93-98. https://doi.org/10.1680/iwtme.1993.23590

[3] Gill, M.A. (1981). Bed erosion in rectangular long contraction. Journal of the Hydraulics Division, 107(3): 273-284.

[4] Laursen, E.M. (1960). Scour at bridge crossings. Journal of the Hydraulics Division, 86(2): 39-54.

[5] Komura, S. (1966). Equilibrium depth of scour in long constrictions. Journal of the Hydraulics Division, 92(5): 17-37.

[6] Webby, M.G. (1984). General scour at a contraction. In: 1984 Bridge Design and Research Seminar. Technical Papers. 23 Authors, 1984; RRU Bulletin 73. Road Research Unit National Roads Board: Wellington, New Zealand, 109-118.

[7] Lim, S.Y., Cheng, N.S. (1998). Scouring in long contractions. Journal of Irrigation and Drainage Engineering, $\quad 124(5)$ : 258-261. https://doi.org/10.1061/(ASCE)07339437(1998)124:5(258)

[8] Dey, S., Raikar, R.V. (2005). Scour in long contractions. Journal of Hydraulic Engineering, 131(12): 1036-1049. https://doi.org/10.1061/(ASCE)07339429(2005)131:12(1036)

[9] Dey, S., Raikar, R.V. (2006). Live-bed scour in long contractions. International Journal of Sediment Research, 21(2): 166-170.

[10] Brandimarte, L., D'Odorico, P., Montanari, A. (2006). A probabilistic approach to the analysis of contraction scour. Journal of Hydraulic Research, 44(5): 654-662. https://doi.org/10.1080/00221686.2006.9521714

[11] Benedict, S.T. (2016). Clear-water abutment and contraction scour in the coastal plain and Piedmont provinces of South Carolina, 1996-99. U.S. Geological Survey, Water-Resources Investigations Report 034064. Columbia, South Carolina, USA.

[12] Mueller, D.S., Wagner, C.R. (2005). Field observations and evaluations of streambed scour at bridges. U.S. Geological Survey, Water Resources Divisions Report No FHWA-RD-03-052. Louisville, Kentucky, USA.

[13] Hayden, J.T., Puleo, J.A. (2011). Near real-time scour monitoring system: application to Indian River inlet, Delaware. Journal of Hydraulic Engineering, 137(9): 1037-1046. https://doi.org/10.1061/(ASCE)HY.19437900.0000399

[14] Oliveto, G., Marino, M.C. (2014). Spatial and temporal variations in bed morphology at river contractions. In: Schleiss, A.J., De Cesare, G., Franca, M.J., Pfister, M. (eds) River Flow 2014. CRC Press/Balkema, Leiden, 
The Netherlands. http://dx.doi.org/10.1201/b17133-196

[15] Oliveto, G., Marino, M.C. (2015). Experimental and numerical investigation of the bed morphology evolution in river contractions. In: Mynett, A. (ed) Proceedings of the $36^{\text {th }}$ IAHR World Congress. Curran Associates, Inc., Red Hook, NY, USA.

[16] Oliveto, G., Marino, M.C. (2016). Bed morphology changes at river contractions. In: Harris, J., Whitehouse, R., Moxon, S. (eds) Scour and Erosion. CRC Press/ Balkema, Leiden, The Netherlands. http://dx.doi.org/10.1201/9781315375045-108

[17] Oliveto, G. (2019). Sediment transport at river contractions. WIT Transactions on Ecology and Environment, 234: 1-7. http://dx.doi.org/10.2495/RBM 190011

[18] Oliveto, G., Hager, W.H. (2002). Temporal evolution of clear-water pier and abutment scour. Journal of Hydraulic Engineering, 128(9): 811-820. https://doi.org/10.1061/(ASCE)07339429(2002)128:9(811)

[19] Graf, W.H., Altinakar, M.S. (1998). Fluvial Hydraulics - Flow and transport processes in channels of simple geometry. John Wiley \& Sons Ltd, Baffins Lane, Chichester, England, 10-12.

[20] Oliveto, G., Marino, M.C. (2019). Morphological patterns at river contractions. Water, 11(8): 1683. https://doi.org/10.3390/w11081683

[21] Lai, Y.G., Greimann, B.P. (2010). Predicting contraction scour with a two-dimensional depthaveraged model. Journal of Hydraulic Research, 48(3): 383-387.

https://doi.org/10.1080/00221686.2010.481846

[22] Oliveto, G., Hager, W.H. (2005). Further results to time-dependent local scour at bridge elements. Journal of Hydraulic Engineering, 131(2): 97-105. https://doi.org/10.1061/(ASCE)07339429(2005)131:2(97)

\section{NOMENCLATURE}

$b$

$D^{*}$

$d_{\mathrm{xx}}$

F

$F_{d}$

$F_{d i}$

$g$

$g^{\prime}$

$h$

$L^{*}$

$l$

$l^{*}$

$Q$

Re

$T$

$t$

$t^{\prime}$

$x$

$X$

$Z$

$Z^{*}$

$z^{*}$

\section{Greek symbols}

$\beta$

$\beta^{\prime}$

$\Delta t$

$v$

$\rho$

$\sigma$

\section{Subscripts}

$\begin{array}{ll}\max & \text { maximum } \\ o & \text { approach } \\ s & \text { sediment }\end{array}$

time, s width of the contracted channel, $\mathrm{m}$ dimensionless grain size

particle size for which $\mathrm{xx} \%$ of sampled particles are smaller than, $m$

Froude number

densimetric Froude number

densimetric Froude number at the incipient movement of the bed sediment grains gravitational acceleration, $\mathrm{m} \cdot \mathrm{s}^{-2}$ modified gravitational acceleration, $\mathrm{m} \cdot \mathrm{s}^{-2}$ flow depth, $m$ dimensionless scour hole length length of the contracted channel, $\mathrm{m}$ scour hole length at a given time, $\mathrm{m}$ discharge, $\mathrm{m}^{3} \cdot \mathrm{s}^{-1}$

Reynolds number

dimensionless time

time for unsteady flow computations, $s$ longitudinal distance, $\mathrm{m}$ dimensionless longitudinal distance dimensionless scour depth dimensionless maximum scour depth scour depth at a given time, $\mathrm{m}$ maximum scour depth at a given time, $\mathrm{m}$

dimensionless contraction ratio dimensionless parameter function of the contraction ratio $\beta$ as $(1-\beta) / \beta$ time step, $\mathrm{s}$ kinematic viscosity, $\mathrm{m}^{2} \cdot \mathrm{s}^{-1}$ mass density, $\mathrm{kg} \cdot \mathrm{m}^{-3}$ dimensionless sediment gradation 